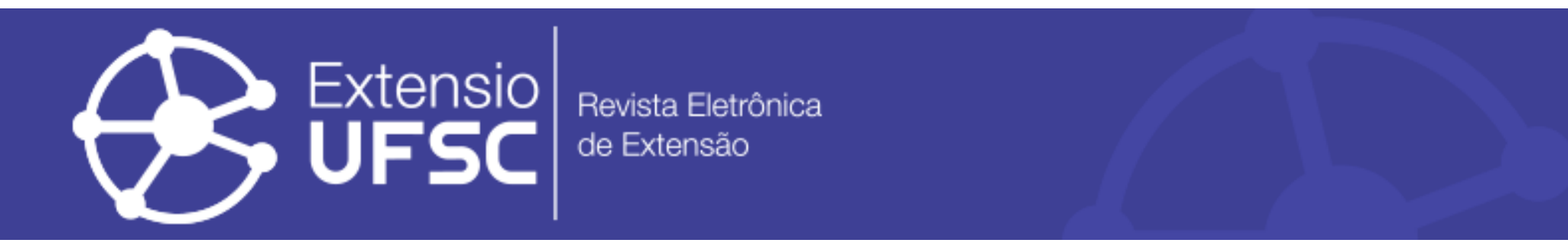

\title{
O PAPEL DA EXTENSÃO NA QUALIFICAÇÃO DOS ESPAÇOS DE ACOLHIMENTO ESTUDANTIL INDÍGENA NA UFSC
}

\author{
Ricardo Socas Wiese \\ Universidade Federal de Santa Catarina \\ ricardo.sw@ufsc.br \\ Nauíra Zanardo Zanin \\ Universidade Federal da Fronteira Sul \\ nauira@nauira.arq.br
}

\section{Resumo}

O artigo apresenta a experiência de uma atividade extensionista que teve como objetivo principal propor soluções arquitetônicas para a qualificação dos espaços de alojamento dos estudantes e famílias indígenas da UFSC, considerando aspectos construtivos, mas também culturais. Este projeto procurou aproximar o curso de Arquitetura e Urbanismo de discussões acerca da temática indígena, buscando conhecer a diversidade cultural dos povos originários do sul do país e promover reflexões acerca do papel social da Arquitetura na construção de espaços para o acolhimento e a valorização da cultura e dos povos indígenas brasileiros na contemporaneidade. $\mathrm{O}$ artigo também destaca o potencial pedagógico da extensão universitária contribuindo de forma significativa aos processos de ensino e aprendizagem promovendo o debate e a interação com o meio social.

Palavras-chave: Moradia Estudantil. Alojamento Indígena. Cultura Indígena. Extensão Universitária.

\section{THE ROLE OF EXTENSION IN THE QUALIFICATION OF INDIGENOUS STUDENT HOST SPACES IN UFSC}

\begin{abstract}
The article presents the experience of an extensionist activity whose main objective was to propose architectural solutions for the qualification of the accommodation spaces of UFSC indigenous students and families, considering constructive as well as cultural aspects. This project aimed to bring the Architecture and Urbanism course closer to discussions about the indigenous theme, seeking to know the diversity of the culture of the indigenous peoples of the south of the country and to promote reflections about the social role of Architecture in the construction of spaces for the reception and valuation of culture and Brazilian indigenous peoples in contemporary times. The article also highlights the pedagogical potential of university extension, contributing significantly to the teaching and learning processes, promoting debate and interaction with the social environment.
\end{abstract}

Keywords: Student Housing. Indigenous Housing. Indigenous Culture. University Extension.

\section{EL PAPEL DE LA EXTENSIÓN EN LA CALIFICACIÓN DE LOS ESPACIOS DE ACOGIDA ESTUDIANTIL INDÍGENA EN LA UFSC}

\section{Resumen}

El artículo presenta la experiencia de una actividad extensionista que tuvo como objetivo principal proponer soluciones arquitectónicas para la calificación de los espacios de alojamiento de los estudiantes y familias indígenas de la UFSC, considerando aspectos constructivos pero también culturales. Este proyecto buscó aproximar el curso de Arquitectura y Urbanismo de discusiones acerca de la temática indígena, buscando conocer la diversidad de la cultura de los pueblos originarios del sur del país y promover reflexiones acerca del papel social de la Arquitectura en la construcción de espacios para la acogida y valorización de la cultura y de los pueblos indígenas brasileños en la contemporaneidad. El artículo también destaca el potencial pedagógico de la extensión universitaria contribuyendo de forma significativa a los procesos de enseñanza y aprendizaje promoviendo el debate e interacción con el medio social.

Palavras clave: Vivienda Estudiantil. Alojamiento Indígena. Cultura Indígena. Extensión Universitaria. 
O papel da extensão na qualificação dos espaços de acolhimento estudantil indígena na UFSC

\section{INTRODUÇÃO}

A extensão universitária é um relevante âmbito de interlocução entre a universidade e o meio social no qual ela se insere. Mediante a obra de Freire $(1983,1996)$, entende-se que a extensão deve ser uma via de mão-dupla entre a universidade e a sociedade, capaz de levantar novas questões e produzir novos saberes.

A ideia de extensão, defendida por Freire, precisa se submeter ao princípio da comunicação. Assim, a interação entre universidade e sociedade passa a se dar pelo diálogo, pelo aprendizado mútuo, e pelo combate às conviç̧ões que justificam a transferência de conhecimento como via de mão única. Segundo Freire, conhecer não é um ato isolado, individual. Conhecer envolve intercomunicação, intersubjetividade. É por meio dessa intercomunicação, mediada pelos objetos a serem conhecidos, que os homens mutuamente se educam, intermediados pelo mundo real (FREIRE, 1996).

Por seu caráter comunicador, a extensão transmite e produz saberes. Ao transmitir, ela complementa a atividade de ensino; e ao produzir, ela fomenta a atividade de pesquisa. Portanto, é fundamental conceber a inserção da universidade, em seu meio social, compreendendo ensino, pesquisa e extensão como inseparáveis (BRANDÃO; WIESE, 2017).

A partir destes princípios estruturadores foi fundamentado o projeto de extensão "Contribuições para a permanência estudantil indígena na UFSC", desenvolvido ao longo do segundo semestre de 2017, no Departamento de Arquitetura e Urbanismo. A experiência e os resultados desta atividade serão relatados neste artigo, buscando evidenciar o papel da extensão universitária como fomentadora do debate acerca da questão indígena na contemporaneidade e seu potencial pedagógico.

Este trabalho tem como ponto de partida uma série de estudos que abordam a questão dos espaços de permanência estudantil na universidade, principalmente envolvendo pesquisas e projetos de extensão acerca da Moradia Estudantil, explorando a potencialidade dos espaços de coletividade e a re-significação deste equipamento institucional e seu papel na contribuição para a comunidade acadêmica (WIESE et al., 2015; 2017).

O contexto deste projeto de extensão é fundamentado a partir de uma parceria com o "Curso Licenciatura Intercultural Indígena do Sul da Mata Atlântica”, promovido pela UFSC, que proporciona a formação superior em licenciatura para indígenas (das etnias Guarani, Kaingang e Laklãno-Xokleng) que atuam em escolas indígenas em diversas aldeias no sul do país. O curso é estruturado em diversos módulos, sob regime de alternância, onde os estudantes indígenas 
desenvolvem parte de suas atividades nas aldeias alternando com períodos de atividade intensiva na universidade, no Campus David Ferreira Lima, em Florianópolis.

Durante o período de atividades no Campus, a universidade fornece alojamento aos acadêmicos indígenas e suas famílias, incluindo crianças, em um espaço improvisado na antiga sede do Grêmio dos servidores da prefeitura do Campus (Ilustração 1). Este espaço, adaptado de maneira rudimentar para receber os estudantes, evidencia a necessidade urgente de uma discussão institucional acerca das condições de permanência dos estudantes indígenas na UFSC.

Diante deste contexto, a coordenação do curso de Licenciatura Indígena apresentou a demanda buscando parceria com a Prof. Nauíra Zanardo Zanin (UFFS) e o Prof. Ricardo Socas Wiese (UFSC) do curso de Arquitetura e Urbanismo, para propor soluções, ainda de caráter provisório, que pudessem garantir melhores condições de habitabilidade ao alojamento, considerando aspectos econômicos, mas também aspectos culturais relacionados aos usuários indígenas.

Diante deste contexto, o objetivo que motivou este projeto de extensão a desenvolver estudos e ações para a promoção de melhores condições de habitabilidade para os estudantes e famílias indígenas do curso de Licenciatura Indígena. Como objetivos resultantes da ação principal, este projeto também intencionou aproximar o curso de Arquitetura e Urbanismo de discussões acerca da temática indígena, buscando conhecer a diversidade da cultura dos povos originários do sul do país e promover reflexões e discussões acerca do papel social da Arquitetura na construção de espaços para o acolhimento e valorização da cultura e dos povos indígenas brasileiros na contemporaneidade.

Sendo assim, o projeto de extensão foi estruturado de maneira a proporcionar novas oportunidades de aprendizado aos estudantes de Arquitetura e Urbanismo através da elaboração e confecção de protótipos de divisórias para o alojamento, levando em consideração aspectos construtivos e culturais. Da mesma forma, foram organizados pequenos eventos de diálogo e troca de saberes, buscando relacionar aspectos da cultura indígena com a arquitetura contemporânea.

Este projeto de extensão representou uma oportunidade valiosa para dar início a uma séria de atividades de integração entre o curso de Arquitetura e Urbanismo com a temática relacionada à cultura indígena e à diversidade dos povos indígenas presentes no sul do país. Ao mesmo tempo, possibilitou um retorno concreto, com efetiva melhoria, para estudantes e famílias indígenas, que atualmente encontram-se alojados em situação precária na UFSC.

Espera-se com estas experiências de extensão, associadas a novas frentes de atuação e pesquisa, contribuir com a melhoria dos alojamentos indígenas na UFSC e promover o debate 
O papel da extensão na qualificação dos espaços de acolhimento estudantil indígena na UFSC

acerca da Moradia Estudantil na UFSC, dando destaque para as políticas de permanência estudantil indígena na instituição.

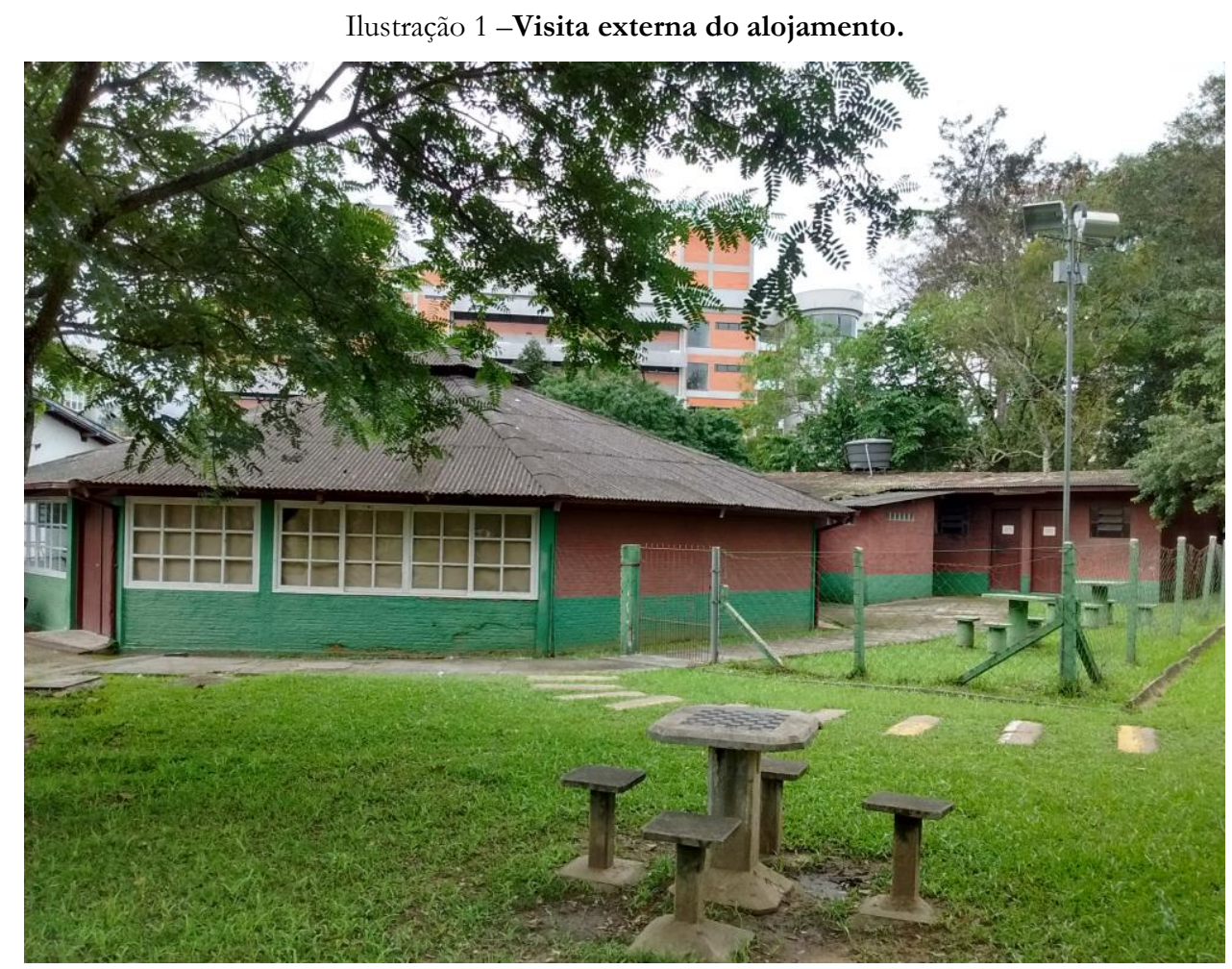

Fonte: Autores, 2017

\section{AS ETAPAS DO PROJETO E SEU DESENVOLVIMENTO}

Diante da necessidade de urgência apresentada pela demanda, o projeto de extensão foi desenvolvido em quatro etapas distintas, contanto com a participação de docentes e técnicos, estudantes indígenas e alunos do curso de Arquitetura e Urbanismo, alternando suas participações em diferentes atividades e momentos.

\section{Etapa 1 - Atividades Iniciais}

A primeira fase teve caráter mais introdutório e de reconhecimento, tendo início com reuniões entre a equipe e representantes do curso de Licenciatura Indígena.

Após as reuniões iniciais, foram feitas visitas técnicas ao espaço que já estava sendo utilizado como alojamento. Nestas visitas, feitas pelos professores responsáveis pelo projeto, foi possível constatar a carência dos espaços e a necessidade de realização de obras de manutenção e reformas na infraestrutura da edificação para garantir minimamente o conforto e a habitabilidade aos estudantes e suas famílias. 
O papel da extensão na qualificação dos espaços de acolhimento estudantil indígena na UFSC

As obras de manutenção e reforma da edificação ficaram sob responsabilidade da Secretaria de Obras, Manutenção e Ambiente (SEOMA) da UFSC, como fechamento de frestas, manutenção das instalações elétricas e reforma dos sanitários.

Neste levantamento inicial, foram feitas as devidas medições e os desenhos que serviram de base para o trabalho. O espaço do antigo Grêmio da Prefeitura do Campus caracteriza-se como um grande galpão, configurado em planta octagonal, e com cobertura estruturada por um grande pilar central. Conectados a este espaço, articulam-se outros espaços anexos, a maioria sem condições de uso para o alojamento.

Para a organização do espaço, o galpão foi dividido com lonas plásticas buscando a divisão em dois setores, um feminino e outro masculino. Em cada setor foram dispostas camas beliches metálicas com estrutura tubular.

Considerando o contexto encontrado, foi solicitado ao grupo o desenvolvimento de uma proposta criativa para melhorar as condições de conforto dos alunos, principalmente, permitindo a divisão do grande salão em módulos menores, confirgurando quartos coletivos. Outro desafio apresentado foi a necessidade de propor soluções de baixo custo, de rápida execução e que poderiam ter caráter provisório.

Ilustração 2 e 3 - Vista interna do alojamento e divisórias em lona.
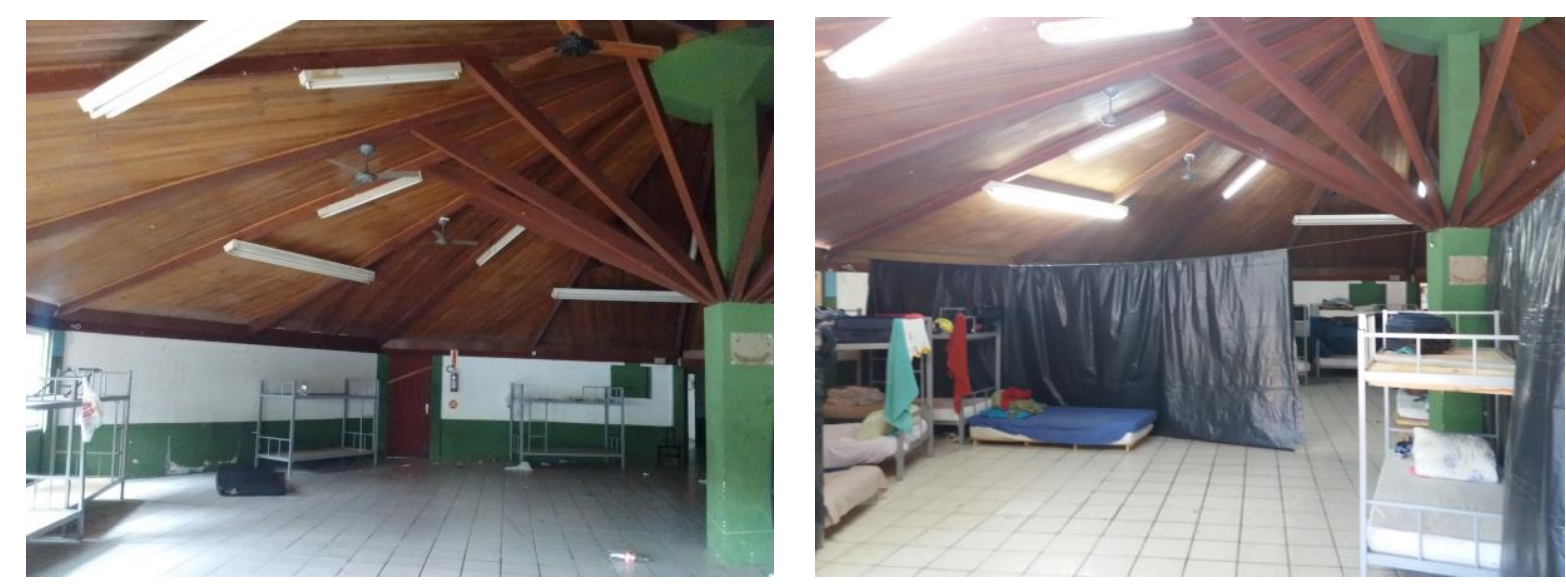

Fonte: Autores, 2017

\section{Etapa 2 - Proposta Arquitetônica}

Após a primeira etapa, com levantamentos no local e definição do objeto de trabalho, foram realizados estudos para uma proposta arquitetônica que atendesse as diversas demandas apresentadas. Muito embora fosse fundamental a participação ativa dos alunos indígenas nesta etapa do trabalho, tal interação não foi possível diante do curto prazo disponível frente à necessidade de qualificar o espaço. Desta forma, a interlocução foi feita diretamente com representantes do curso de Licenciatura Indígena e o trabalho baseado na experiência prévia dos 
docentes e pesquisadores envolvidos no projeto. As propostas para a qualificação do espaço e o projeto arquitetônico de divisórias para a organização espacial do alojamento foram desenvolvidos seguindo algumas diretrizes:

(1) Garantir flexibilidade na divisão dos espaços, permitindo que a organização deste possa ser discutida diretamente com os acadêmicos indígenas, considerando suas necessidades e respeitando questões culturais.

(2) Permitir que os próprios estudantes indígenas possam imprimir sua identidade nos painéis. Desta forma, as divisórias poderão se transformar em suportes para serem pintados ou ornados com acessórios que tragam significado e identificação com espaço (Ilustração 4 e 5).

(3) Os suportes inferiores dos painéis de divisória formam triângulos que remetem a ponta de flechas dos povos indígenas, simbolizando suas lutas constantes para garantir sua sobrevivência e seus direitos.

(4) Utilizar materiais naturais e de baixo custo, chapas de madeira de compensado naval e peças de eucalipto maciças, viabilizando sua execução emergencial e que podem ser reutilizados como painéis para exposições caso não fossem mais necessários.

Para além destes aspectos, o projeto de divisão e distribuição do espaço considerou a organização do espaço em módulos de dormitórios, distribuídos ao redor de um espaço central, proporcionando um ambiente circular de convívio no centro (Ilustração 6).

Os módulos de dormitórios podem abrigar até cinco camas beliche ou serem unidos, criando módulos maiores, permitindo outras configurações de organização dos estudantes, de acordo com seus próprios critérios.

Cabe ressaltar que cada módulo foi pensado de modo a garantir que a disposição das camas se aproximasse de um círculo, distribuídas junto às paredes e divisórias, permitindo que todos possam olhar uns para os outros. Esta forma de organizar as camas foi identificada durante a etapa inicial de levantamento, onde foi possível constatar que os estudantes buscavam organizar seus grupos em círculos e nunca dispondo fileiras de camas lado a lado.

Outro aspecto interessante é que os beliches disponibilizados pela universidade não tinham suas camas superiores utilizadas, pois os estudantes não se adaptaram a este tipo de cama. Em suas casas, muitos dos estudantes indígenas utilizavam redes ou camas baixas para dormir e, por tais motivos, alguns retiravam os colchões dos beliches no alojamento e os colocavam no chão para conseguirem dormir.

Considerando estes aspectos e a impossibilidade de substituição dos beliches neste momento, foi proposta a utilização apenas das camas inferiores e aproveitando a estrutura destes como dosséis para a instalação de telas mosquiteiro (outro grande problema destacado pelos 
O papel da extensão na qualificação dos espaços de acolhimento estudantil indígena na UFSC

estudantes). A parte superior do beliche poderá ser então utilizada como prateleira para o estudante organizar seus pertences.

Ilustração 4 e 5 - Módulos de painéis de divisória.
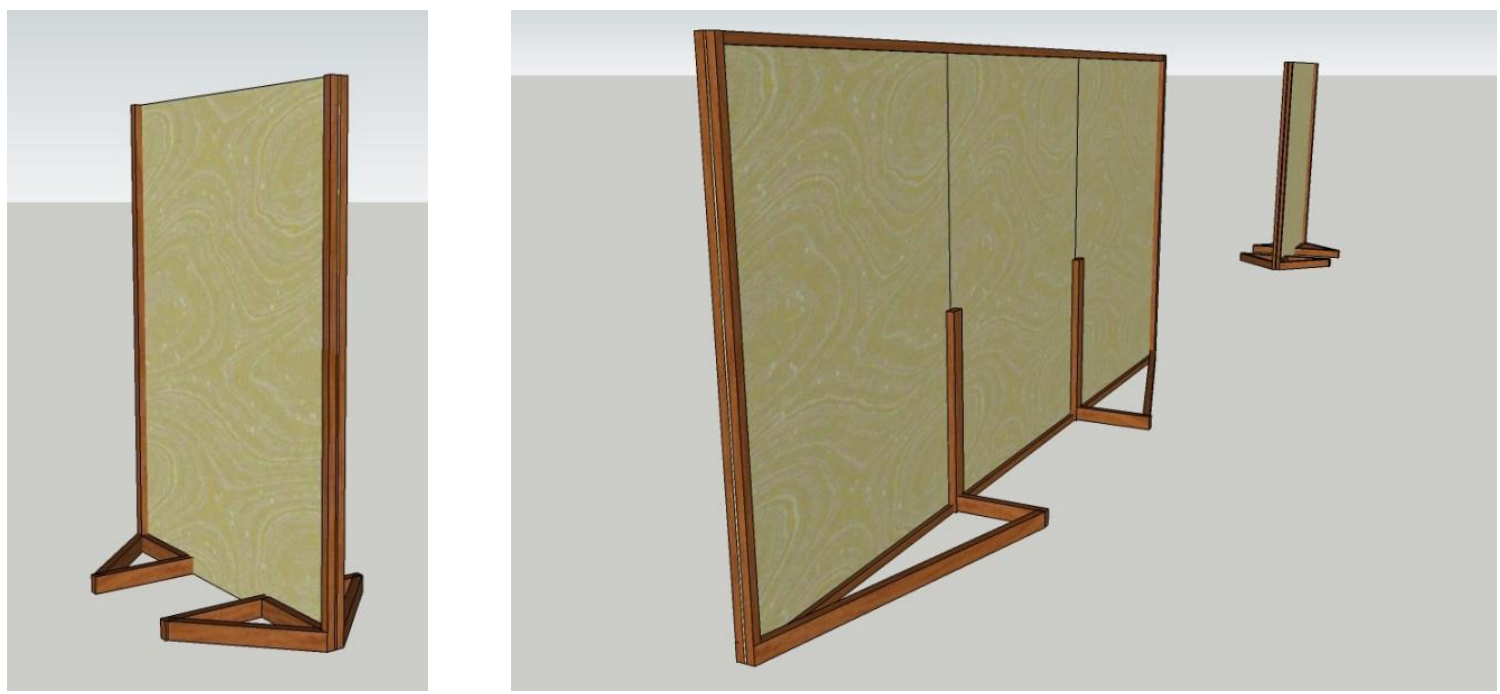

Fonte: Autores, 2017

Ilustração 6 - Projeto de organização do espaço com novas divisórias.

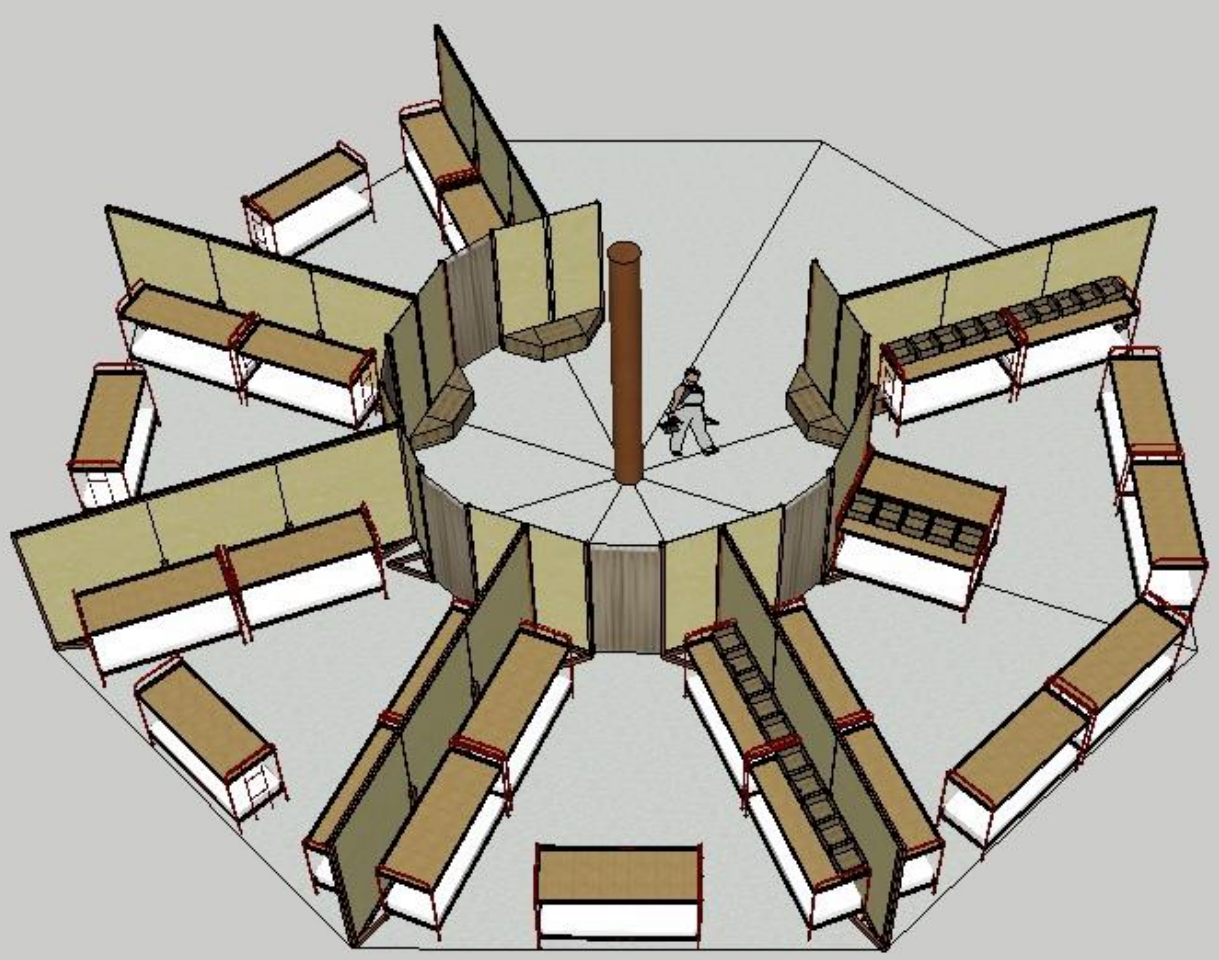

Fonte: Autores, 2017

\section{Etapa 3 - Oficina Prática}


O papel da extensão na qualificação dos espaços de acolhimento estudantil indígena na UFSC

Síveres (2008) enfatiza que a extensão é um recurso de aprendizado também para quem a ministra, sendo fundamental neste processo a articulação dos três segmentos envolvidos: docentes, discentes e a comunidade externa. Seguindo estes princípios, nesta etapa foi possível efetivar o envolvimento direto dos acadêmicos do curso de Arquitetura e Urbanismo nas atividades propostas neste projeto buscando potencializar os processos de aprendizado.

A participação dos estudantes foi viabilizada com a organização de uma ação de extensão no formato de Oficina Prática como atividade integrante da Semana Acadêmica do curso de Arquitetura e Urbanismo, no mês de novembro de 2017. Esta ação de extensão, para além de envolver os estudantes do curso no projeto, também teve como objetivo aproximar os mesmos da temática dos povos indígenas e sua presença nos espaços universitários da UFSC.

A Oficina Prática foi desenvolvida em duas etapas, com a presença de cerca de dez estudantes do curso de Arquitetura e Urbanismo. A primeira consistiu em uma visita ao espaço do alojamento para que pudessem conhecer as condições de permanência dos estudantes indígenas e ter a oportunidade de dialogar com alguns deles e conhecer um pouco de sua história (Ilustrações 7 e 8)

Ilustração 7 e 8 - Oficina Prática: Visita ao alojamento.
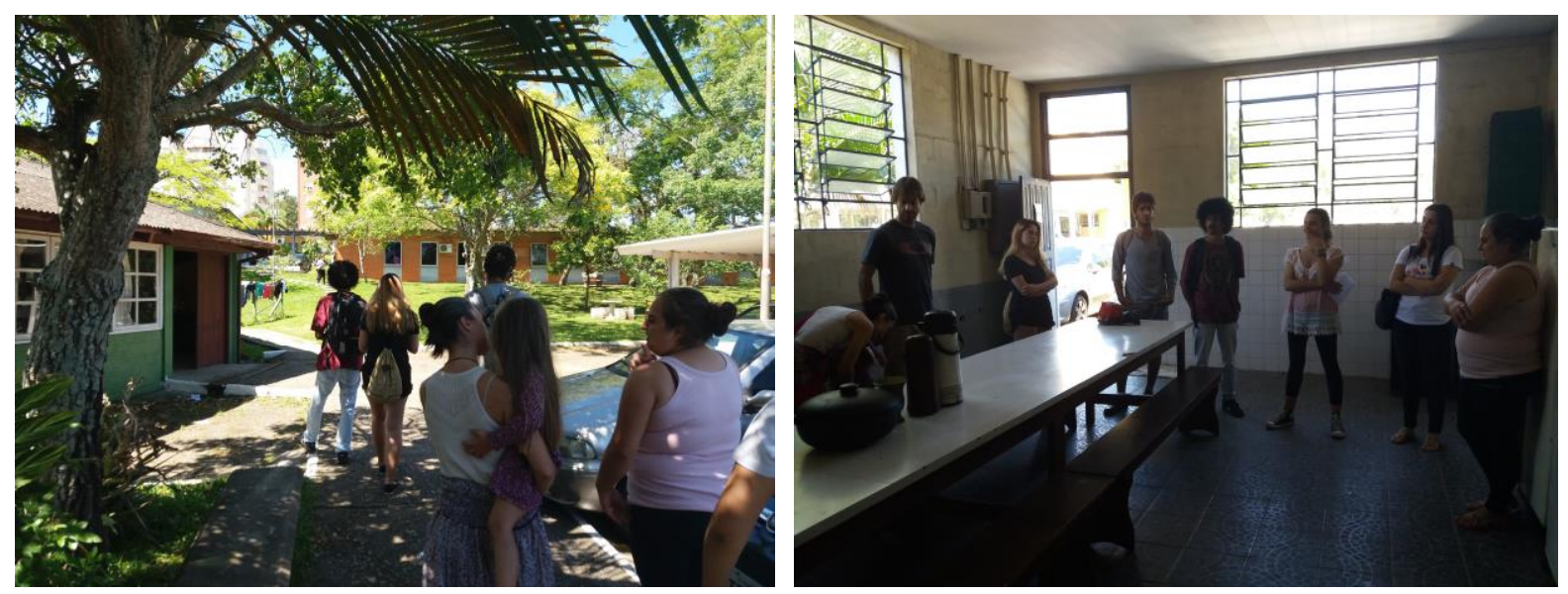

Fonte: Autores, 2017

A segunda etapa da Oficina orientada aos estudantes de arquitetura e urbanismo, realizada no Laboratório de Modelos e Maquetes (LabMoMa), com o desenvolvimento de detalhes construtivos e a execução de um protótipo de divisória em escala real (Ilustrações 9, 10, 11 e 12). Esta atividade de extensão permitiu potencializar aspectos do ensino curricular do curso de Arquitetura e Urbanismo aproximando os estudantes de questões relacionadas à materialidade construtiva da arquitetura e à tectônica de elementos que compõem as edificações. Neste exercício prático abordaram-se questões relacionadas ao reconhecimento do material a ser 
O papel da extensão na qualificação dos espaços de acolhimento estudantil indígena na UFSC

utilizado e suas possibilidades de aplicação, desenvolvendo soluções técnicas construtivas adequadas e garantir a estruturação e estabilidade do elemento construído (Ilustrações 13 e 14).

Após o final do processo de construção, este protótipo está servindo como modelo para a equipe da Prefeitura do Campus produzir as demais divisórias que deverão ser montadas até a metade do ano de 2018.

Ilustração 9 e 10 - Oficina Prática no LabMoMa: construção das divisórias.

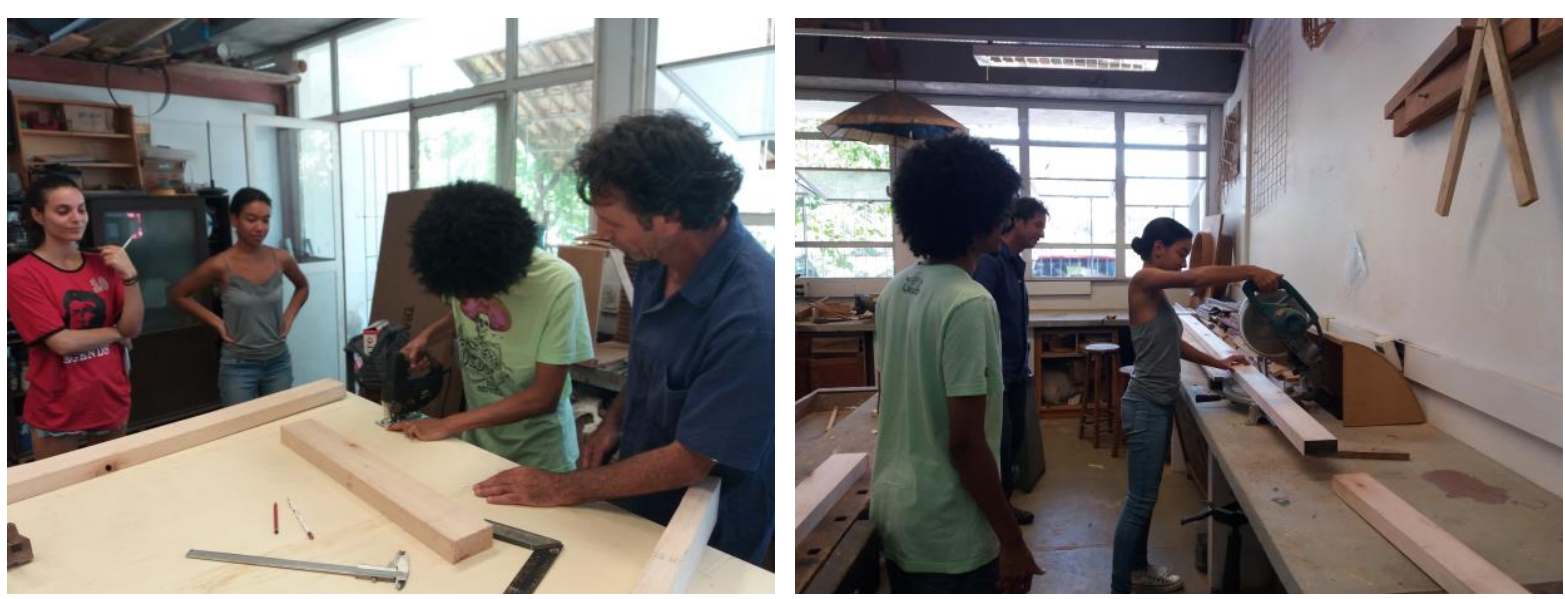

Fonte: Autores, 2017

Ilustração 11 e 12 - Oficina Prática no LabMoMa: construção das divisórias.

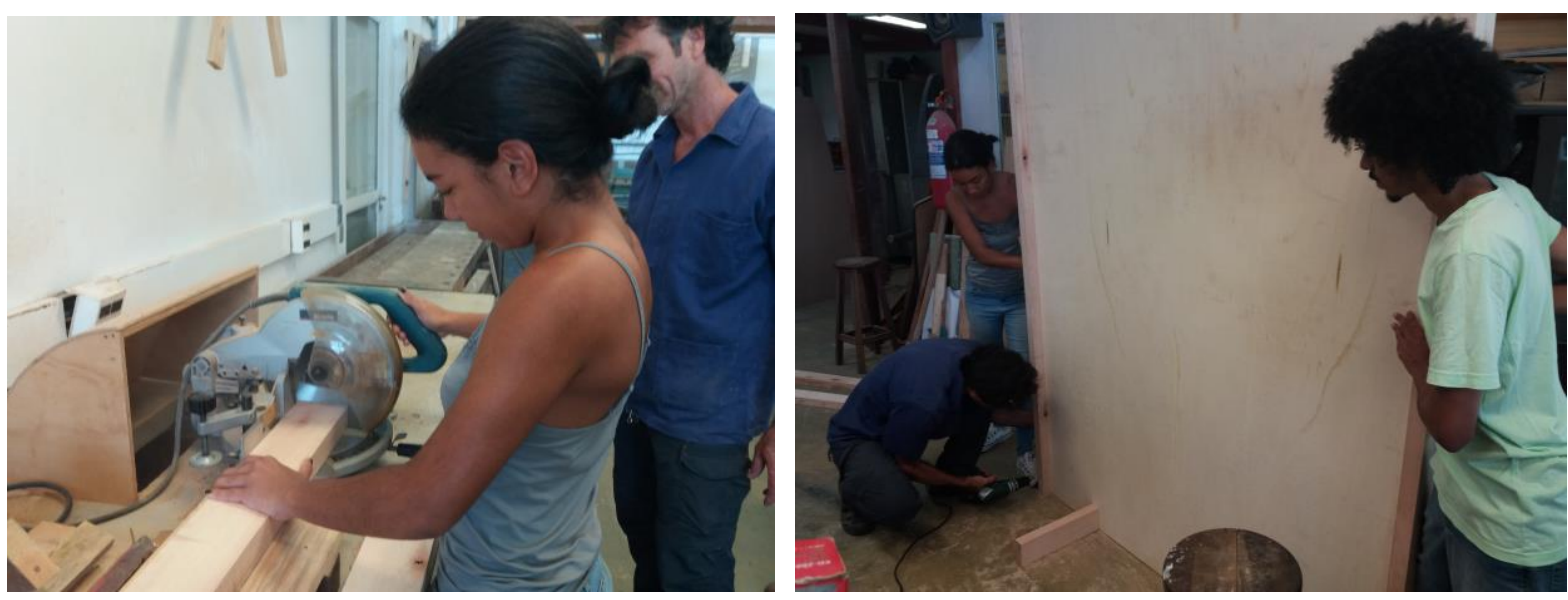

Fonte: Autores, 2017 
O papel da extensão na qualificação dos espaços de acolhimento estudantil indígena na UFSC

Ilustração 13 e 14 - Oficina Prática no LabMoMa: detalhes construtivos.
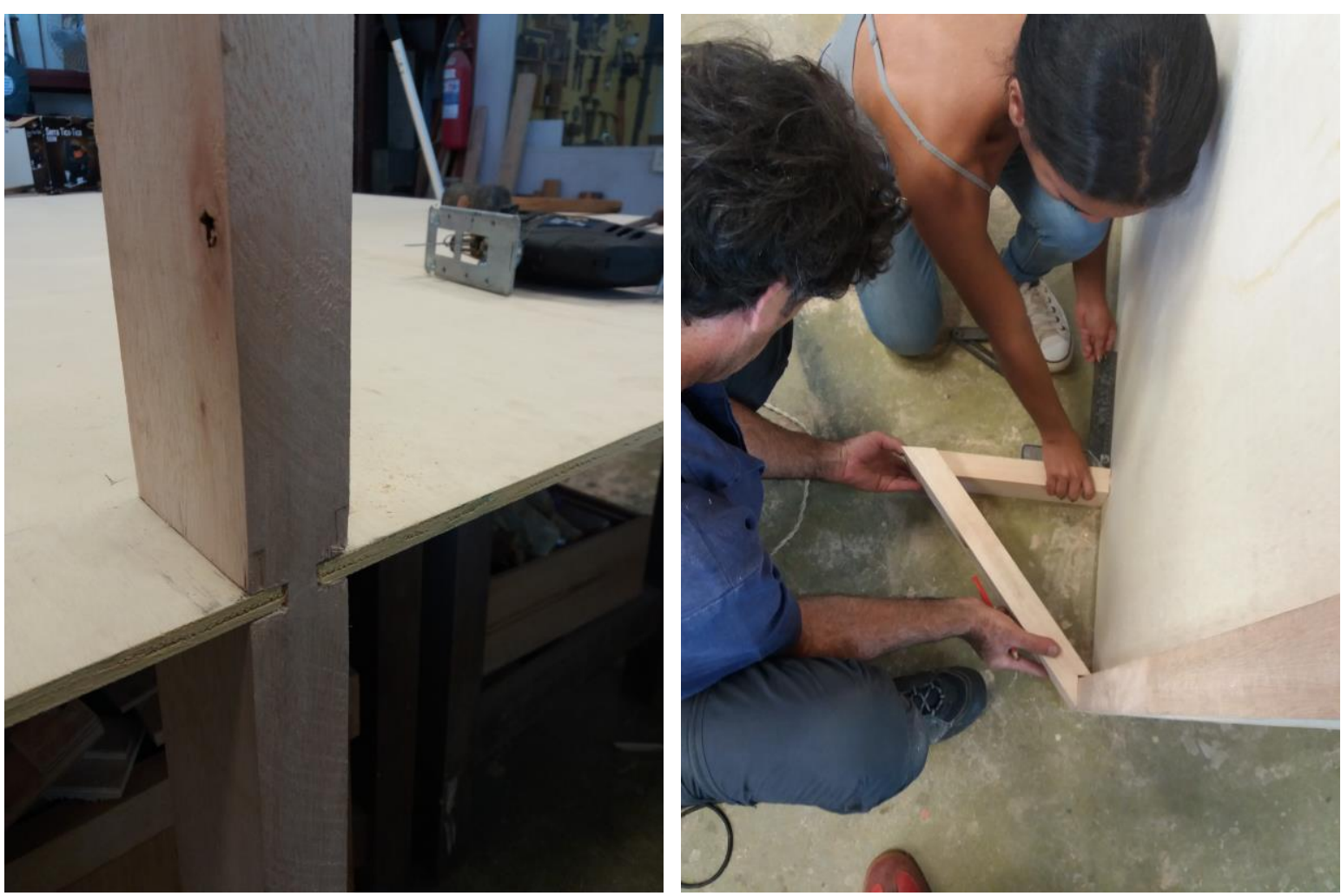

Fonte: Autores, 2017

\section{Etapa 4 - Integração e Debate}

Buscando ampliar a discussão acerca da Moradia Estudantil e os espaços de permanência para os estudantes indígenas na universidade, foi organizado um evento aberto, em parceria com a Secretaria de Ações Afirmativas e Diversidade (SAAD) e a participação de vários estudantes indígenas regulares de cursos de graduação da UFSC.

O evento teve como título "Roda de Conversa: Espaços de acolhimento para a presença indígena no Campus Universitário" e aconteceu no dia 22 de novembro de 2017 no Hall do prédio do Departamento de Arquitetura e Urbanismo.

Como participação especial, o evento contou com uma palestra da Arquiteta Prof. Nauíra Zanardo Zanin, da Universidade Federal da Fronteira Sul (UFFS), com a temática de "Espaços de acolhimento para indígenas em campi universitários". Após a palestra houve a abertura de uma roda de conversa com a presença da direção da SAAD, estudantes indígenas regulares dos cursos de graduação e estudantes e docentes do curso de Arquitetura e Urbanismo, discutindo sobre as 
O papel da extensão na qualificação dos espaços de acolhimento estudantil indígena na UFSC

condições de permanência do estudante indígena na UFSC e os projetos de Moradia Estudantil indígena e do Centro de Convivência e Valorização da Cultura Indígena.

Esta atividade contribuiu significativamente aos objetivos do projeto e o tema do evento se mostrou de grande relevância para a UFSC e para a garantia da permanência dos estudantes indígenas na universidade. Desta forma, foi possível despertar o interesse de outros estudantes do curso de Arquitetura e Urbanismo para contribuírem em novas frentes de pesquisa e extensão envolvendo a temática.

\section{RESULTADOS E ENCAMINHAMENTOS}

Ao final desta experiência de extensão, o projeto arquitetônico desenvolvido foi apresentado aos estudantes indígenas do curso de Licenciatura Intercultural Indígena do Sul da Mata Atlântica, em um evento realizado no início do ano de 2018. O retorno dos estudantes sobre o projeto foi positivo, sendo destacado o caráter de flexibilidade e possibilidade de modificação, adaptação e interação com os usuários.

A SEOMA agora está em processo de produção dos elementos construtivos, utilizando a infraestrutura da prefeitura do Campus.

A experiência deste projeto de extensão permitiu desdobramentos, com a estruturação de

novas frentes de atuação, envolvendo estudantes do curso de Arquitetura e Urbanismo e estudantes indígenas regulares da graduação, buscando integrar atividades de ensino, pesquisa e extensão.

Para Dewey (apud AMARAL, 2007), educar é mais do que a mera reprodução de conhecimentos, é incentivar o desejo de desenvolvimento contínuo e preparar indivíduos capazes de transformar realidades problemáticas.

\section{CONSIDERAÇÕES FINAIS}

Assim como destacado por Freire (1980), por meio da extensão a academia tem a possibilidade de contribuir em questões reais da sociedade e, ao mesmo tempo, abrir novas portas de interlocução, ampliando oportunidades de pesquisa e aprendizado.

A experiência relatada neste artigo demonstra a diversidade de ações que podem ser exploradas em um projeto de extensão, criando e experimentando formas de aprendizado e de interlocução com as questões que permeiam nossa sociedade. 
O papel da extensão na qualificação dos espaços de acolhimento estudantil indígena na UFSC

Através da extensão foi possível introduzir questões até então pouco debatidas internamente no curso de Arquitetura e Urbanismo e dar início a novas frentes de pesquisa e extensão que deverão ser desenvolvidas de forma integrada entre os estudantes do curso e acadêmicos indígenas da UFSC.

Destaca-se ainda, que tais experiências podem ser incorporadas a atividades do currículo do curso, por meio da inserção das temáticas desenvolvidas na extensão em atividades das próprias disciplinas, ou pelo desenvolvimento de atividades complementares às atividades de extensão.

A extensão, assim, permite que possamos extrapolar os limites inicialmente impostos pelas grades curriculares, ampliando as possibilidades de aprendizado e, ao mesmo tempo, aproximar o curso de novos debates, necessários e contemporâneos, potencializando as oportunidades de integrar a pesquisa ao ensino por meio da extensão.

\section{REFERÊNCIAS}

AMARAL, M. N. C. P. Dewey: Filosofia e Experiência Democrática, São Paulo: Perspectiva, 2007. 136 pg.

FREIRE, Paulo. Extensão ou Comunicação. São Paulo: Paz e Terra, 1980.

Pedagogia da Autonomia - Saberes Necessários à Prática Educativa. 36 ed. São Paulo: Editora Paz e Terra, 2007.

SÍVERES, Luiz. Perspectivas de Aprendizagem na Extensão Universitária In: SÍVERES, Luiz (Org.). Processos de Aprendizagem na Extensão Universitária. Goiânia: Editora PUC, 2012.

BRANDAO, L. F. L. M.; WIESE, R. S. Extensão universitária em comunidades associativas: potencialidades pedagógicas dos assentamentos do Movimento dos Trabalhadores Rurais sem Terra, o caso de Pontão-RS.. In: XVII ENAMPUR - Encontro Nacional da Associação Nacional de Pós-Graduação e Pesquisa em Planejamento Urbano e Regional, 2017, São Paulo. Anais do ENAMPUR, 2017.

WIESE, Ricardo Socas; PEREIRA, N. B. ; YAMAUCHI, V. . A prática projetual como laboratório de ensino, pesquisa e extensão e sua contribuição para a qualidade no ensino de arquitetura e urbanismo da UFFS. Cadernos ABEA, v. 40, p. 1-755, 2015.

WIESE, Ricardo Socas; ZIN, J. P. ; SILVA, E. B. V. ; ZIMERMANN, K. G. . Moradia Estudantil: Território da Coletividade.. In: XVII ENAMPUR - Encontro Nacional da Associação Nacional de Pós-Graduação e Pesquisa em Planejamento Urbano e Regional, 2017, São Paulo. Anais do ENAMPUR, 2017.

WIESE, Ricardo Socas; ZIN, J. P. ; SILVA, E. B. V. . A POTENCIALIDADE DA MORADIA ESTUDANTIL COMO ESPAÇO DE INTEGRAÇÃO COM A CIDADE. In: $4^{\circ}$ CIHEL 
O papel da extensão na qualificação dos espaços de acolhimento estudantil indígena na UFSC

Congresso Internacional da Habitação no Espaço Lusófono, 2017, Porto e Covilhã - Portugal. Anais do Congresso Internacional da Habitação no Espaço Lusófono, 2017.

Recebido em: 28/05/2018

Aceito em: 30/07/2018 